\title{
Use of a second ventilatory circuit when using a double-lumen endotracheal tube
}

\author{
Jean Bussières, MD, FRCPC · Catherine Cournoyer, MD, FRCPC • \\ Etienne J. Couture, MD, FRCPC
}

Received: 2 March 2020/Revised: 5 March 2020/Accepted: 7 March 2020/Published online: 6 April 2020

(c) Canadian Anesthesiologists' Society 2020

\section{To the Editor,}

We read with interest the correspondance of Dr. Bruin concerning the use of a second respiratory circuit and a leak test when using a double-lumen endoracheal tube (DLT). ${ }^{1}$ His report adds to the initial description of a second circuit to administer continuous positive airway pressure during onelung ventilation (OLV) that was published by Scheller and Varvel in $1987 .^{2}$ We described our own version of the second circuit in the Journal in $2014^{3}$ mainly used to re-expand the lung during and following OLV. Indeed, there are are at least two other variations of the leak test reported in the literature, including the "bubble test" from Benumof in 1987. ${ }^{\mathrm{A}}$ In this method, air bubbles are detected by placing one end of a soft suction tubing in the non-ventilated lumen of the DLT while the other end is placed underwater. In presence of an air leak from the ventilated lung, air bubbles will be observed under the water. The other variation - the "balloon method" was described by Brodsky and Mark in 1993 for detecting an inadequate DLT cuff seal. ${ }^{4}$ In this method, a finger is cut from a small (size 6) latex glove and fitted snugly over the open lumen of the non-ventilated channel of the DLT. If incomplete lung separation occurs, each tidal volume breath will make the latex balloon inflate.

This letter is accompanied by a reply. Please see Can J Anesth 2020; 67: this issue.

J. Bussières, MD, FRCPC $(\bowtie) \cdot$ C. Cournoyer, MD, FRCPC .

E. J. Couture, MD, FRCPC

Institut universitaire de cardiologie et de pneumologie de

Québec-Université Laval, Quebec City, QC, Canada

e-mail: jbuss@criucpq.ulaval.ca

Departement d'anesthésiologie et de soins intensifs-Université Laval, Quebec City, QC, Canada
All these leak tests share similarities with the leak test described by Dr. Bruin. As a final option, it is important to consider the potential for using continuous spirometry (integrated into every anesthesia machine) to detect an air leak. ${ }^{5}$ This technique may detect any small leaks from the bronchial cuff. It expresses the leak as an interruption of the spirometry curves and as a reduction in the expiratory volume compared with inspiratory volume. This technique is probably easier to use than the second circuit technique and is certainly more objective. Nevertheless, spirometry only effectively detects leak from the ventilated lung when the endobronchial aspect of the DLT is positioned in the ventilated lung.

Finally, we would like to show an updated version of our own second circuit set-up (Figure). We use an oxygen blender to adjust the fraction of inspired oxygen $\left(\mathrm{F}_{\mathrm{I}} \mathrm{O}_{2}\right)$ of the gas flow administrated to the non-dependant lung. During surgery, when the surgeon requests a small inflating volume to verify clamping of the bronchus, we use an $\mathrm{F}_{\mathrm{I}} \mathrm{O}_{2}$ of 1.0 to accelerate the re-collapse of the lung after OLV ventilation resumes. At the time of final re-inflation of the operative lung, we use an $\mathrm{F}_{\mathrm{I}} \mathrm{O}_{2}$ of 0.21 to minimize any postoperative atelectasis. Final re-inflation using a $\mathrm{F}_{\mathrm{I}} \mathrm{O}_{2}$ of 0.21 instead of a $\mathrm{F}_{\mathrm{I}} \mathrm{O}_{2}$ of 1.0 could also be accomplished by adding an oxygen blender to the montage proposed by $\mathrm{Dr}$ Bruin.

The presence of a second respiratory circuit is very useful during OLV and ideally could be added by manufacturers of anesthesia machines. This would offer an important option for anesthesiologists performing thoracic anesthesia.

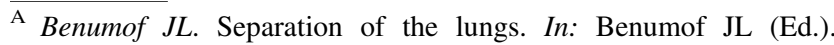
Anesthesia for Thoracic Surgery. W.B. Saunders Co.; 1987: 251.
} 


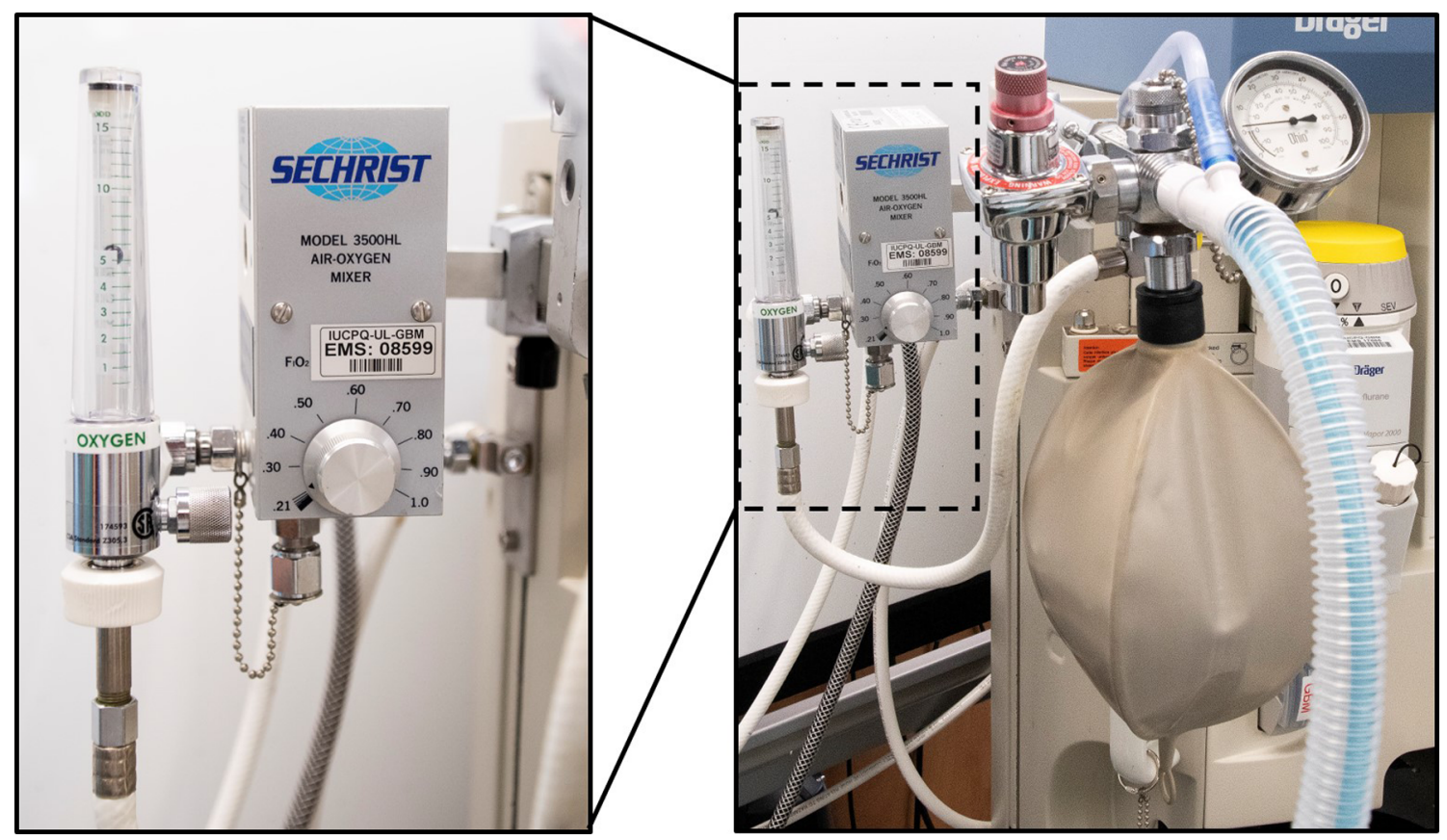

Figure An oxygen blender can be used alongside the flowmeter to regulate the fraction of inspired oxygen administered to the non-ventilated lung

\section{Conflicts of interest None.}

\section{Funding statement None.}

Editorial responsibility This submission was handled by Dr. Hilary P. Grocott, Editor-in-Chief, Canadian Journal of Anesthesia.

\section{References}

1. Bruin G. Advantages of a second ventilation circuit when using a double-lumen endotracheal tube. Can J Anesth 2020; . https://doi. org/10.1007/s12630-019-01553-y.
2. Scheller MS, Varvel JR. CPAP oxygenation during one-lung ventilation using a Bain circuit. Anesthesiology 1987; 66: 708-9.

3. Bussières JS, Ugalde PA. Lung re-inflation after one-lung ventilation for thoracic surgery: an alternative technique. Can $\mathbf{J}$ Anesth 2015; 62: 424-6.

4. Brodsky JA, Mark JB. Balloon method for detecting inadequate double-lumen seal cuff seal. Ann Thor Surg 1993; . https://doi.org/ 10.1016/0003-4975(93)91122-4.

5. Bardoczky GI, Levarlet $M$, Engelman E, deFrancquen $P$. Continuous spirometry for detection of double-lumen endobronchial tube displacement. Br J Anaesth 1993; 70: 499-502.

Publisher's Note Springer Nature remains neutral with regard to jurisdictional claims in published maps and institutional affiliations. 